Theories \& Applications, the International Edition

Printed Version : (ISSN 2090-5262)

Online Version : (ISSN 2090-5270)

November 2014, Volume 4, No. 3 Pages (90 - 96)

\title{
Effect of functional resistance Drills with Elastic bands on performance of Release Phase in Shot Put Competition.
}

\section{Dr. Khaled Waheed Ibrahem}

Assistant professor, Sports training department, Faculty of Physical Education, Mansoura University, Egypt.

\begin{abstract}
This study aimed to determine the effects of functional resistance drills with elastic bands on performance of release phase in shot put competition. Experimental method is used. Among male college students of Mansoura University, five men's outdoor track and field student-athletes at Physical Education College were taken as purposive sample. functional resistance drills with elastic bands were used during the specific prep phase of training with duration of 8 weeks (3 training units per week for 2hrs), reps (8-12), and (3-5) sets.After the functional resistance drills end date, dimensional measurements, kinematic analyses were carried out. A Statistical Data Analysis was carried out. Through results presentation and discussion it was possible to conclude the Functional resistance drills with elastic bands leads to improve some of the physical variables of the sample under study. These variables include maximal strength, leg muscle power, speed-strength and balance. As well as Functional resistance drills with elastic bands leads to improve some of the kinematic variables of release phase where the Mean height of the release $(221.80 \mathrm{~cm})$, the Mean of release velocity $(9.58 \mathrm{~m} / \mathrm{s})$ the Mean of angle release (40.20 deg), Mean of throwing distance $(13.06 \mathrm{~m})$ of the study sample in Shot Put competition.
\end{abstract}

Key words : functional resistance - elastic bands - Release Phase - Shot Put

\section{Introduction:}

$\mathrm{S}$ hot Put competition is requires the thrower to exploit any part of a thrower's body and to ensure that all body movements are completed accurately; it accelerates and decelerates according to human movement's kinematic rules.However, the successful Technique for Shot Put Throwing depends greatly on what happens during the release phase. The ball must both be at a higher level and behind the pelvis as long as possible, taking into account the appropriate release angle (Turk ,1997). During the throw phase, the left foot of the right thrower should be behind the stop board and on the inner side, right foot should be near the center of shot put circle, shoulder facing the back of the circle, trunk tends to the rear of circle (Khairia El Sokkary, \& Sulaiman Hassan, 1997). So, throwing position is one of the most important, but also the most difficult stages of shot put because when the shot put moves towards the throwing direction, it should go in a straight line and do not deviate toward any other direction as well as the centre of gravity of the shot should be in the same direction (Zaki darwish \& Adel Abdel Hafez, 1994). The height of release, angel of release and speed of release are undoubtedly the most important factors in determining the distance of a throw. Speed of release is the most important of these factors (linthorne 2001, Khalid Waheed, 2004). Achieving the highest release velocity, it must work on gathering strength, accelerating the shot in the throwing circle (Sloan, 1995). For the shot put, the optimum release angle is 42- 44 degrees (Hubbard et al., and others, 2001). According to the Laws of Motion, if it is considered that Shot Put throw distance is constant, release speed decreases (1.7) $\mathrm{m} / \mathrm{s}$ for each increase $(1 \mathrm{~m})$ in release height and Put throw distance decreases ( $1.7 \mathrm{~m}$ ) for each one-degree increase in release height (Hubbard et al., 2001).Balance is one of the motor elements that must be considered when training motor skills. It is considered one of the basic components of motor skill. It is impossible to perform a sporting skill well if it is not linked to balance (Baumgarther \& Jackson, 1999) , (Carr, 1994). Balance is the ability to retain the center of mass when moving from one point to another (Davis, et.al ,1997). Balance is the result of several body systems working together which is located primarily in the inner ear. Degeneration or loss of function in any of these systems can lead to balance deficits; it is responsible for the motor balance. The length of time that the episode of loss of balance lasts demonstrates device efficiency and individual's balance level (Mohamed Talaat, 1984).As functional resistance training becomes a more popular method to improve muscular fitness, and has been considered to be a better alternative than traditional resistance training for improving various measures of muscular fitness including strength, endurance, coordination and balance (Tiana Weiss, et al., 2010).Functional resistance training defines as a mix of all two types of training; Training for strength and balance at the same time. It is also an integrated and multi-level drills (Horizontal, sagittal, vertical) (Fabio Comana, 2004). It is suitable for all individuals at different levels of training and aims to improve the relationship between the muscles and the nervous system (Vom Hofe,1995). The focus of a 
traditional drills program is to increase the strength or endurance of a particular muscle or muscle group without regard to training movements that are related to activities of daily living or sport performance. While Functional training uses many joints and muscles of the upper and lower body during each movement (Tiana Weiss,et al. 2010).

Functional training programs consist of three main components:

1. Core stability

It is a few repetitions of each of the movement by moderate drills with gradual progress of performance and aims to achieve self-consistency and neuromuscular control.

\section{Core Strength}

It is dynamic movements using external resistors in all levels of motor and aims to achieve muscle strength and motor integration.

\section{Core Power}

It is a movement characterized by producing power characterized by a velocity (Michael Boyle, 2004).

The functional resistance training could serve as an alternative and potentially more creative method for improving performance in young adults compared to more traditional drillss and could possibly be applied to people of all ages and physical abilities. The overall data indicated that functional training can enhance muscular strength endurance and balance, which are variables usually associated with programs that involve more traditional resistance training drillss. In addition, it may be possible to maintain or enhance flexibility through functional resistance training due to the nature of the drills (multi-joint with focus on full range of motion) (Tiana Weiss,et al., 2010)

Elastic bands offer variable resistance throughout a range of motion and their incorporation with drills movements has long been used for rehabilitation purposes. More recently, however, elastic bands have found a niche in many strength programs because of the purported performance benefits (Wallace, BJ,et al., 2006). It is already clear the importance of resistance training with elastic bands to improve the level of performance compared to more traditional drills. So the present study aimed to determine the effects of functional resistance drills with elastic bands on the physical variables and some of the kinematic variables of release phase in the glide style of shot put competition. In non-probability sampling, 5 Third-year men's track and field student-athletes at Mansoura University have been chosen. while hypothesis of this study was that functional resistance drills with elastic bands positively affect physical variables and some of the kinematic variables of release phase in the glide style of shot put competition.

Methods : Experimental method was used; in a singlegroup experiment, a pre-test and a post-test in Track \& Field of Olympic Village Mansoura - athletic hall in Physical Education College - University of Mansoura, and the functional drillss and the pretest-posttest are done during the 10-week training program for the glide style of shot put competition, and sample was intentionally selected form Third-year men's track and field student-athletes at Physical Education College Mansoura University and consisted (5) student .

Kinetic analysis was performed using computer-assisted analysis according to the following steps:

1. Six Attempts at Photography per thrower with registering throwers' numbers, according to the order of their performance and their successful and unsuccessful attempts.

2. Preparing attempts for kinetic analysis; the most successful attempts for each thrower have been determined. Then, These data were entered to Computer to start the process of analysis motion.

3. Kinematic variables of the release phase were determined by using the program for the analysis motion (video point 2.5 ).

4. The pre-test measures: Tests were made during the period $28-29$ September, 2013. It was assured that values of research variables are fair and unbiased before starting the experiment as shown table (1), (2).

Table (1)

statistical characterization of the sample in basic and physical variables under study

$\mathbf{N}=\mathbf{5}$

\begin{tabular}{|c|c|c|c|c|}
\hline Variables & $\begin{array}{c}\text { Unit of } \\
\text { measure }\end{array}$ & Mean & $\begin{array}{c}\text { Standard } \\
\text { Deviation }\end{array}$ & $\begin{array}{c}\text { Skewness } \\
\text { coefficient }\end{array}$ \\
\hline Age & $($ Year $)$ & 20.60 & 0.42 & 0.72 \\
\hline Height & $(\mathrm{Cm})$ & 185.60 & 2.70 & 0.67 \\
\hline Weight & $(\mathrm{Kg})$ & 88 & 3.81 & 0.00 \\
\hline Muscle strength for back extensors & $(\mathrm{Kgf})$ & 192 & 5.70 & 1.05 \\
\hline Muscle strength for legs extensors & $(\mathrm{Kgf})$ & 269 & 6.52 & $0.46-$ \\
\hline Wide jump from stability & $(\mathrm{Cm})$ & 245.35 & 3.63 & 0.99 \\
\hline High jump from stability & $(\mathrm{Cm})$ & 45.35 & 3.90 & 0.92 \\
\hline
\end{tabular}




\begin{tabular}{|c|c|c|c|c|}
\hline Variables & $\begin{array}{c}\text { Unit of } \\
\text { measure }\end{array}$ & Mean & $\begin{array}{c}\text { Standard } \\
\text { Deviation }\end{array}$ & $\begin{array}{c}\text { Skewness } \\
\text { coefficient }\end{array}$ \\
\hline shot put in front of body & $(\mathrm{M})$ & 10.55 & 0.51 & $1.17-$ \\
\hline shot put in back of body & $(\mathrm{M})$ & 12.40 & 0.52 & $0.58-$ \\
\hline Off-balance feeling Duration & $(\mathrm{S})$ & 8.64 & 0.42 & $0.78-$ \\
\hline
\end{tabular}

It is evident from Table (1) that all the Skewness values of above data set are between $-3,+3$, indicating to fair value measures.

Table (2)

statistical characterization of of the sample in some kinematic variables of release phase in the glide style of shot

$$
\text { put competition } \quad \mathrm{N}=5
$$

\begin{tabular}{|c|c|c|c|c|}
\hline Variables & $\begin{array}{c}\text { unit of } \\
\text { measure }\end{array}$ & Mean & $\begin{array}{c}\text { Standard } \\
\text { Deviation }\end{array}$ & $\begin{array}{c}\text { Skewness } \\
\text { coefficient }\end{array}$ \\
\hline Release height & $(\mathrm{Cm})$ & 211.20 & 2.77 & 1.30 \\
\hline release speed & $(\mathrm{M} / \mathrm{s})$ & 8.71 & 0.54 & $1.60-$ \\
\hline release angle & $(\mathrm{Deg})$ & 34.60 & 1.14 & $1.05-$ \\
\hline throwing distance & $(\mathrm{M})$ & 11.64 & 0.40 & $0.43-$ \\
\hline
\end{tabular}

It is evident from Table (2) that all the Skewness values of above data set are between $-3,+3$, indicating to fair value measures.

Implementation of baseline study: functional resistance drills with elastic bands has been applied using during the specific preparation phase of the training program for glide style of shot put competition in the period from $09 / 30 / 2013$ to $12 / 09 / 2013$ for (10) weeks by (3) training units per week for $2 \mathrm{hrs}$. Apps of functional resistance Training using bands include:

\section{1 - Upper body drills}

- Chest Press \& Single Leg Chest Press :Stand on one leg and lean forward with each arm straight in front of your chest, holding a TRX handle so that the TRX hangs diagonally. Keeping your body long and tall, bend your elbows to lower your body toward the TRX handles. Push yourself back up to the starting position.

- Chest Fly: Stand facing away from the anchor point. Lean forward. Hold handles with palms facing each other and arms extended slightly below shoulders. Keep the elbows slightly bent and simply open. Close the arms bringing the hands out in front of the body.

- Atomic Push Up :Assume Push-Up position with feet in TRX straps. Perform Push-Up with control, keeping back flat. Tuck knees into chest and return to start position with control.

- Back Row (low, 45 deg., \& high): Stand with your feet pointed straight ahead and draw in your navel. Bend at your waist until your chest is at a 45 degree angle to the ground. Extend your arms and let them hang in front of your body with a dumbbell in each hand.

- Deltoid Fly "W" \& Deltoid Fly" T": Find end range of "I" position with arms extended overhead and body nearly upright. Keep tension on TRX®. Step back into offset foot stance, with weight on forward leg. Lean back. Extend arms forward and shifting weight to rear leg. Pull arms directly overhead into "I" position by squeezing shoulder blades together. Body weight will shift to front leg. Keep arms straight.

- Triceps Press: Face away from anchor point. Hold handles with palms facing down and arms extended. Hands are at eye-level. Lean forward. Keep hands separated. Bend elbows until hands are behind head. Return to start position by driving hands forward until arms are straight.

- High Biceps Curl: Face anchor point. Hold handles with arms extended. Lean back. Bend elbows until hands are next to temples, with palms facing forehead. Return to start position with arms straight. Keep elbows high throughout movement.

\section{Lower Body Drills}

- Single Leg Balance Squat: Perform a single leg squat. Face anchor point with legs together and left foot lifted slightly. Hold handles with elbows bent and at sides.

- Suspended Lunge: Face away from anchor point. Place right foot into both foot cradles at once, toes in. Plant left foot approximately three feet in front of anchor point. Press suspended foot down into foot cradle. Lower hips into lunge position. Suspended leg will move back. Keep weight on heel of grounded foot. Press down on heel of grounded foot.

- Hamstring Curl ( hips lifted): Place heels in foot cradles directly under anchor point. Press down with heels into foot cradles. Lie on back with arms at sides and palms flat on ground. Use core and to lift hips. Draw heels toward hips while lifting hips and squeezing glutes.

\section{Core Strength and Stability Drills}

High Back Extension: Grab the TRX handles and step back away from the anchor point while facing it, creating tension on the straps with palms facing down, 
hand close to shoulder. With feet shoulder-width apart, drop into a deep squat. Excel up out of the squat, pulling arm up to a "V" pattern.

- High Torso Rotation : Grasp onto the single TRX handle with an overlapping grip. Step forward until your body is at 45 degree angle, or close to. Rotate your torso by driving your hands to one side, while keeping your arms straight throughout. Return back to center position and rotate the opposite way.

- Kneeling Rollout : Kneels facing away from anchor. Hands on handles, body upright. Turn lower body to " 10 o'clock" or "2 o'clock" position; upper body faces front. Slowly drive arms up and lean forward from knees, keeping core engaged. Return to start position, maintaining body alignment.

- Leg Raise: Lie face-up on the floor and grasp the handles above your chest. Raise your legs until the torso makes a 90-degree angle with the legs. Rotate your hips to the right and lower your legs, keeping them together at all times. Stop before your legs reach the floor. At the bottom of your movement the back of your right hip should be on the floor and your toes should point to your right. Lift your legs back to the starting position, retracing their downward path.

- uspended Pike from Hands: Adjust straps so that they are hanging about a 12 " to 18 " above the floor. With feet in the straps, get in the push-up position with abs lower back flat, and hands straight under shoulders. Pull your body upward thinking of bringing your feet toward your armpits, without bending your knees. Aim to get your core and rear aligned over your shoulders. With full control, lower body to starting position and repeat.
- Suspended Pendulum: Place your feet in the handles and get into a push-up position. Swing your legs side to side while keeping your hips in line with the rest of your body.

- Suspended Side Plank with Reach Through : Lay on the floor and put your feet in the foot cradles. Move onto your right hip, support your upper-body with your right elbow and forearm. Straighten your legs so that you are in a side-plank position with your feet off the floor. Then lift your left hand toward the sky with your head looking toward the sky too. Next, bring the left hand underneath touching a point on the ground behind the elbow. Bring your left arm back upward to the sky again reaching as far as you can.

In our application process, we take into account that:

- Focus should be on strengthening the upper and lower limb muscles ; firming and strengthening core muscles

- Stretching drills should be used at the end of each training drills to gain the full effects of stretching.

- Mixed methods are used; you can see highintensity training Circuit training system.

- Circuit training includes (5) training, 8-12 reps. and 3-5 sets.

- Control of resistance training load and intensity through the change between time of performance and rest period between sets of an drills.

The post-test measures: On 10 November 2013.

Statistical Data Processing: - Mean - Standard Deviation

- Coefficient of skewness

Wilcokson test - the critical value $\mathrm{z}$

Results:

Table (3)

The Statistical Significance of Differences between pre-/post-tests for physical variables after the experiment $\quad \mathrm{N}=5$

\begin{tabular}{|c|c|c|c|c|c|c|c|}
\hline \multirow[b]{2}{*}{ Variables } & \multirow{2}{*}{$\begin{array}{c}\text { unit of } \\
\text { measure }\end{array}$} & \multicolumn{2}{|c|}{ Pre-test } & \multicolumn{2}{|c|}{ Post-test } & \multirow[b]{2}{*}{ Wilcokson } & \multirow[b]{2}{*}{$\mathrm{z}$} \\
\hline & & Mean & $\begin{array}{c}\text { Standard } \\
\text { Deviation }\end{array}$ & Mean & $\begin{array}{c}\text { Standard } \\
\text { Deviation }\end{array}$ & & \\
\hline Muscle strength for legs extensors & (Kgf) & 269 & 6.52 & 295 & 4.18 & 0.00 & $* 2.060$ \\
\hline Wide jump from stability & $(\mathrm{Cm})$ & 245.35 & 3.63 & 258.20 & 2.86 & 0.00 & $* 2.023-$ \\
\hline shot put in front of body & (M) & 10.55 & 0.51 & 11.51 & 0.40 & 0.00 & $* 2.023$ \\
\hline shot put in back of body & $(\mathrm{M})$ & 12.40 & 0.52 & 13.15 & 0.65 & 0.00 & $* 2.041-$ \\
\hline Off-balance feeling Duration & (S) & 8.64 & 0.42 & 4.94 & 0.26 & 0.00 & $* 2.023-$ \\
\hline
\end{tabular}

$\mathrm{V}$ of the Wilcokson at Significance level $0.05=17$

Z-score value at Significance level $0.05=1.96$

It is evident from Table 3) that there is Significant differences at the 0.05 level in all physical differences. The calculated value of the Wilcokson was less than its tabulated value. The table also shows that $\mathrm{z}$-value (the critical value of significance) was higher than tabulated value at 0.05 . 
Table (4)

The Statistical Significance of Differences between pre-/post-tests for kinematic variables of the release phase in the glide shot put $\quad \mathrm{N}=5$

\begin{tabular}{|c|c|c|c|c|c|c|c|}
\hline \multirow{2}{*}{ Variables } & \multirow{2}{*}{$\begin{array}{c}\text { unit of } \\
\text { measure }\end{array}$} & \multicolumn{2}{|c|}{ Pre-test } & \multicolumn{2}{|c|}{ Post-test } & \multirow{2}{*}{$\begin{array}{c}\text { Wilcokson } \\
\text { value }\end{array}$} & \multirow{2}{Z}{$\begin{array}{c}\text { Z } \\
\text { value }\end{array}$} \\
\cline { 3 - 8 } & & Mean & $\begin{array}{c}\text { Standard } \\
\text { deviation }\end{array}$ & Mean & $\begin{array}{c}\text { Standard } \\
\text { deviation }\end{array}$ & & \\
\hline Release height & $(\mathrm{Cm})$ & 211.20 & 2.77 & 221.80 & 2.86 & 0.00 & $* 2.032-$ \\
\hline Release velocity & $(\mathrm{M} / \mathrm{s})$ & 8.71 & 0.54 & 9.58 & 0.49 & 0.00 & $* 2.041-$ \\
\hline Release angle & $(\mathrm{Deg})$ & 34.60 & 1.14 & 40.20 & 1.30 & 0.00 & $* 2.041-$ \\
\hline Throwing distance & $(\mathrm{M})$ & 11.64 & 0.40 & 13.06 & 0.40 & 0.00 & $* 2.023-$ \\
\hline
\end{tabular}

$\mathrm{V}$ of the tabulated Wilcokson at Significance level $0.05=17$

Z-score value at Significance level $0.05=1.96$

It is evident from Table (4) that there is Significant differences at the 0.05 level in all kinematic variables. The calculated value of the Wilcokson was less than its tabulated

value. The table also shows that $z$-value (the critical value of significance) was higher than tabulated value at 0.05 .

Figure (1)

illustrates some kinematic variables of release phase in the glide shot put competition to one sample from the same population after the experiment.

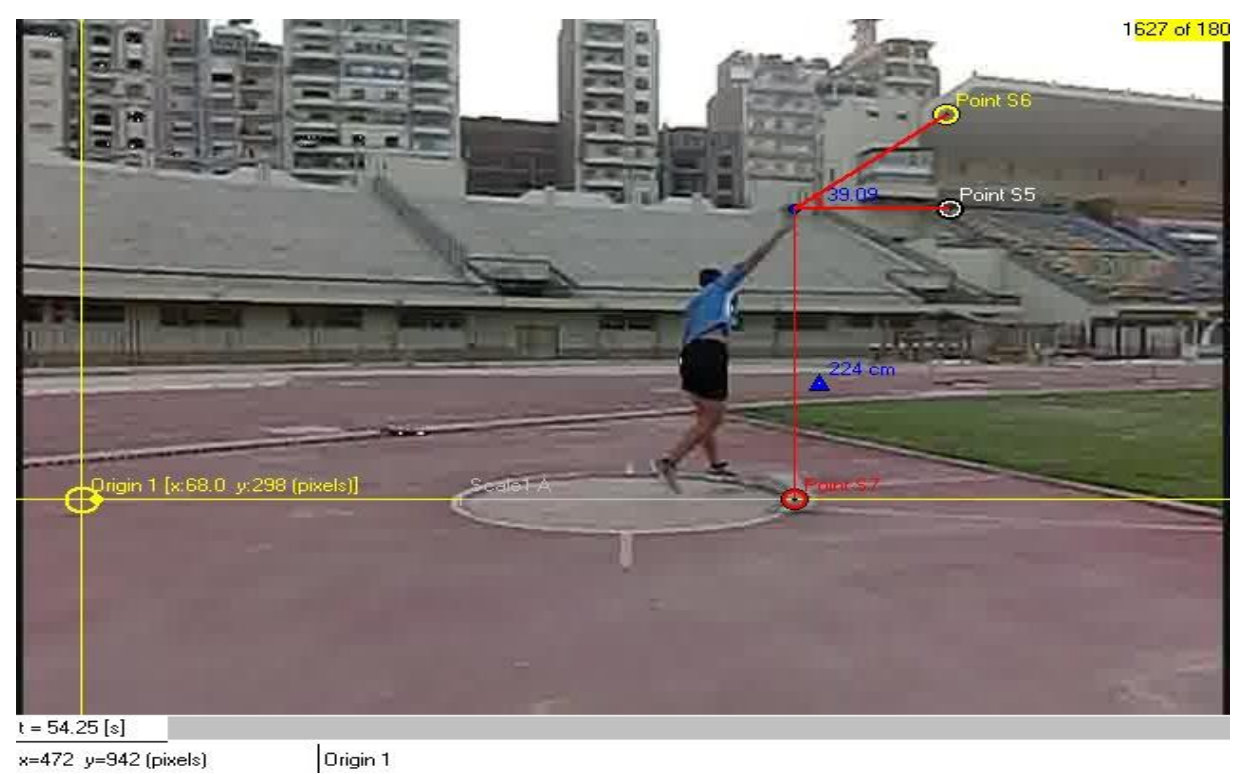


Figure (1) some kinematic variables of release phase in the glide shot put competition to one sample from the same population after the experiment.

\section{Discussion}

It is evident from Table (3) that the calculated value of the Wilcokson was less than its tabulated value. The table also shows that $z$-value was higher than tabulated value at 0.05 and there is Significant differences at the 0.05 level in all physical differences for the post-dimension. So, the researcher returned that to the effectiveness of the functional resistance drills with elastic bands which had been applied using during the specific preparation phase of the training program for glide style of shot put competition which helped to increase strength, speed, power and motor balance. Where, that was completely consistent with those obtained by (Tiana Weiss, et al., 2010) . And, the functional strength drillss suit all individuals with different levels and aims to improve the relationship between the muscles and the nervous system. Where, that was completely consistent with those obtained by (Vom Hofe,1995). Michelle Boyle (2004) said that Functional training programs lead to improve muscle strength, neuromuscular control, integration of motor and speed-strength .

It is evident from Table (4) that there is Significant differences at the 0.05 level in all kinematic variables for the post-dimension. The researcher returned that the effectiveness of the functional resistance drills with elastic bands which have been applied using during the specific preparation phase of the training program for glide style of shot put competition on increasing the strength, speed, power and motor of the upper /lower muscles and core muscles which helped to improve the kinematic variables of release phase. These results are completely consistent with those obtained by (Tiana Weiss, et, al,. 2010). The functional resistance training could serve as an alternative an potentially more creative method for improving performance in young adults . (Baumgarther \& Jackson 1999) and (Carr, 1994) together mention that the balance with agility and motor control, is one of the essential components necessary to produce superior athletic performance. (Michael Boyle, 2004) said that the functional drills programs lead to improve muscle strength, control neuromuscular, integration of motor and speed-strength. (Sloan, 1995) said that the maximum rate of release speed depends on the technique used, assembling forces and work on increasing the acceleration of Shot Put during the transition into the throwing circle. The throw distance shown in table (4) indicates an improvement of release speed and release angle, which led to an increase of throwing distance. This result was entirely consistent with that obtained by (Frossard, \& al, 2003); (linthorne, 2001). These results suggest that release height, release angle and release velocity are the most important factors that have the greatest impact on shot put throw distance and the release speed is the key factor affecting the shot put distance.

\section{Conclusions:}

Through results presentation and discussion it was possible to conclude the Functional resistance drills with elastic bands leads to improve some of the physical variables of the sample under study. These variables include maximal strength, leg muscle power, speed-strength and balance. As well as Functional resistance drills with elastic bands leads to improve some of the kinematic variables of release phase where the Mean height of the release $(221.80 \mathrm{~cm})$, the Mean of release velocity $(9.58 \mathrm{~m} / \mathrm{s})$, the Mean of angle release (40.20 deg), Mean of throwing distance $(13.06 \mathrm{~m})$ of the study sample in Shot Put competition

\section{Recommendations:}

- Using functional resistance drills with elastic bands within training programs of thrower.

- Diversity in the application of functional resistance drills with elastic bands for upper and lower extremities and core muscles because of its positive impact on technical performance.

- The need for power measurements of upper and lower extremities, core muscles, balance and analysis motion, as well as working on improving them during different training periods.

\section{References}

1. Baumgarther,T \& Jackson,A (1999) : Measurement for Evaluation in physical Education and Drills Science,6th,ed,McGraw Hill,Boston, .pp231.

2. Carr,C., (1994) : Mechanics of Sport , Apractitioner's Guide, Human Kinetics, Champaign, .pp88.

3. Davis,B.,Bull,Roscoe,J.,\& Roscos,D., (1997) : Physical Education and the Study of Sport,3rd,ed,Mosby, London, .pp116.

4. Fabio Comana (2004): function training for sports, Human Kinetics: Champaign IL, England,.pp27 .

5. Findley BW.(2004):Training with bands bands. Strength Cond J 26: pp 68-69 .

6. - Hubbard, , M., Neville, J., and Scott, J., (2001) : Dependence Of Release Veriables In The Shot Put, Journal Of Biomechanics, Vol 34 , issue 4, April, pp . $449-456$.

7. Khalid Wahid Ibrahim, (2004) : The effect of using pushing machine on some kinematic variables for release in shot put competition, Eighth International Scientific Conference for Physical Education and Sports Science, second part , Faculty of Physical Education for Men, Alexandria University, October 5 to 7 pp. 730-755. (In Arabic)

8. Khairia El Sokkary, \& Sulaiman Hassan., (1997) : A Guide of Learning and Training in Throw competition, Dar Elmarf, Alexandria . pp . 45 . (In Arabic)

9. Linthorne, N., (2001): Optimum Release Angle In The Shot Put, Journal Of Sport Sciences Taylor, Francis Ltd, Vol 19 ,issue 5. pp . 359 - 372 . 
10. Michael Boyle (2004) : Functional Balance Training Using a Domed Device ,j Spine, 21, pp2640-2650 .

11. Mohamed Talaat Ibrahim,(1984) : Suggestion Training Program for Improvement Boxers Balance, Sports for Everybody Conference , Faculty of Physical Education for Men, Helwan University, Egept . pp .319. (In Arabic)

12. Sloan,R. (1995) : Developing Shot Put Technique, Track and Field Coaches Review, Vol 95, No 3 . pp .34 .

13. Tiana Weiss, Jerica Kreitinger, Hilary Wilde, Chris Wiora, Michelle Steege Lance Dalleck, Jeffrey Janot ., (2010) : Effect of Functional Resistance Training on Muscular Fitness Outcomes in Young Adults, J Exerc Sci Fit . Vol 8 . No 2 .pp 113-122.
14. Turk, M., (1997) : Building Technical Model Of The Shot Put, Track Coach, No 141, Fall . pp .4798 4798.

15. - Vom Hofe, A.(1995): The problem of skill specificity in complex athletic tasks: A revisitation. International Journal of Sport Psychology 26, pp249-261.

16. Wallace, BJ, Winchester, JB, and McGuigan, MR. , (2006) : Effects of elastic bands on force and power characteristics during the back squat drills. Journal of Strength Condation Resistance, 20: pp 268-272.

17. Zaki darwish \& Adel Abdel Hafez, 1994) : Encyclopedia of athletics, throwing and compound competition, Dar El-Maaref, Alexandria. P.77 (In Arabic). 
